\title{
Contribuições teóricas de Cremilda Medina para pensar complexamente o jornalismo
}

\section{Rafael Rangel Winch'}

\section{Resumo}

Este artigo tem como objeto de estudo as contribuições teóricas de Cremilda Medina referentes à atividade jornalística. Com o propósito de compreender como a perspectiva da autora entende e explica conceitualmente o jornalismo, examina-se sua obra e reflete-se acerca de seus principais postulados. Destaca-se a noção de diálogo social que busca pensar o fazer jornalístico para além dos seus componentes técnicos. O olhar complexo e relacional defendido por Cremilda Medina é apresentado, discutido e contraposto a algumas críticas à sua obra. Entre outras considerações, esta pesquisa identifica a preocupação da pesquisadora em teorizar o jornalismo sem relegar dimensões mais amplas do fenômeno, como a comunicação e a cultura.

Palavras-chave: Jornalismo. Cremilda Medina. Diálogo Social.

\section{Abstract}

This paper has as object of study theoretical contributions of Cremilda Medina concerning the journalistic activity. In order to understand how this author's perspective understands and explains journalism conceptually, we examine her academic production and reflect on her main postulates. We emphasize the notion of social dialogue that think journalistic activity beyond its technical components. The complex and relational look defended by Cremilda Medina is presented, discussed and contrasted with some criticism about her perspective. Among other considerations, this research identifies the researcher's concern to theorize journalism without relegating broader dimensions of the phenomenon, such as communication and culture.

Keywords: Journalism. Cremilda Medina. Social Dialogue.

\footnotetext{
1 Jornalista. Doutorando do Programa de Pós-Graduação em Jornalismo da Universidade Federal de Santa Catarina (PPGJOR/UFSC). Bosista FAPESC/CAPES. E-mail: rangelrafael16@hotmail.com
}

Revista Pauta Geral-Estudos em Jornalismo, Ponta Grossa v.5, n.2, p.89-105, Jul/Dez 2018. 


\section{Introdução}

O artigo aponta e discute algumas das principais contribuições da pesquisadora e jornalista Cremilda Medina no que concerne as dimensões teórica e prática do jornalismo. Trata-se de uma autora que atravessou cinco décadas refletindo sobre diferentes aspectos e dilemas que caracterizam a profissão, sem nunca deixar de lado o olhar complexo, dialógico e plural. Desde já é oportuno alertar que embora Cremilda Medina não reivindique um espaço teórico autônomo - com estatuto conceitual autossuficiente para analisar o fenômeno jornalístico, seus escritos reconhecem especificidades que configuram este fazer como uma atividade particular da chamada comunicação social. Metodologicamente, o estudo se orienta a partir de uma revisão bibliográfica, que contempla a leitura sistemática e crítica da produção téórica de Cremilda Medina sobre o jornalismo e suas interfaces.

Organizamos esta reflexão da seguinte maneira: a) Primeiramente, discorremos brevemente acerca de alguns fatos que marcam a carreira da pesquisadora; $b$ ) Apresentamos uma síntese das primeiras abordagens da autora sobre o jornalismo, resultados de suas primeiras incursões teóricas; c) Examinamos como a questão da dialogia social é inicialmente mobilizada para pensar a atividade jornalística de modo relacional; d) Refletimos sobre como o paradigma positivista está presente na gramática jornalística, bem como discutimos a noção de narrativa, mediação e autoria; e) Por fim, tecemos breves considerações sobre os contributos teóricos de Cremilda Medina. No desenrolar do artigo, ainda destacamos e tensionamos críticas de outros pesquisadores à perspectiva da autora.

\section{Uma trajetória aberta ao outro}

Cremilda Medina nasceu em Portugal, no contexto da Segunda Guerra Mundial. Aos dez anos se mudou com a família para o Brasil, instalando-se em Porto Alegre, em 1953. Já em 1960, foi aprovada em Jornalismo pela Universidade Federal do Rio Grande do Sul (UFRGS). No ano seguinte, passou em Letras Clássicas na mesma instituição. 
Frequentou os dois cursos ${ }^{2}$, atendendo seus diversos interesses teóricos e profissionais manifestos desde então. Inquietações e questionamentos sociais que afloram nos anos 1960 estimularam discussões sobre o lugar do sujeito jornalista na sociedade. Eram tempos de resistência cultural, momento em que as finalidades do jornalismo e do ensino da profissão passaram a ser mais problematizadas no espaço acadêmico. O período assinala também o expressivo crescimento da presença das mulheres no ensino superior brasileiro (MEDINA, 2015). A data em que Cremilda Medina se forma como jornalista localiza-se no fatídico e simbólico 31 de março de 1964, dia do golpe militar que interrompeu a democracia no Brasil por mais de vinte anos.

Entre 1967 e 1970, obteve sua primeira experiência como docente no curso de Jornalismo da UFRGS. Após esses anos lecionando, deixa Porto Alegre em busca de aperfeiçoamento como professora e pesquisadora. Assim, ingressa como auxiliar de ensino, em 1971, na Escola de Comunicações e Artes, da Universidade de São Paulo (USP). Essa época marca o início do seu contato com instituições do exterior, bem como do trabalho junto a nomes importantes da pesquisa em comunicação no Brasil, como José Marques de Melo, que nesse período já se dedicava a aprofundar as relações entre teoria e prática jornalística. A primeira grande investigação autoral de Cremilda Medina, o livro $A$ Arte de Tecer o Presente, nasce em 1973, em parceria com Paulo Roberto Leandro. Dois anos depois, em 1975, ela se torna a primeira mestra em comunicação na América Latina pela USP, universidade que tem o primeiro curso de pós-graduação na área em solo latino-americano. No mesmo ano, a autora abre mão do vínculo institucional por conta, sobretudo, das perseguições e abusos da ditadura.

Durante dez anos, Cremilda Medina se dedicou prioritariamente à atividade profissional, sendo repórter e editora em veículos como o jornal O Estado de S. Paulo. Atuando como jornalista, em 1978, publica a obra Notícia, um Produto à Venda, Jornalismo na Sociedade Urbana e Industrial, onde discute especialmente as condições de produção do gênero basilar da atividade jornalística. Ao passo em que o regime militar dava sinais de término, em meados dos anos 1980, a autora e outros colegas retomaram seus trabalhos, em tempos de reconstrução democrática. Em 1986 retorna à USP onde

2 Ao longo desse período na UFRGS, Cremilda Medina foi colega do jornalista e escritor Sinval Medina. Os dois se casaram e permanecem juntos até o presente momento (MEDINA, 2015).

Revista Pauta Geral-Estudos em Jornalismo, Ponta Grossa v.5, n.2, p.89-105, Jul/Dez 2018. 
continua até hoje se dedicando exclusivamente às atividades de pesquisa e ensino. $A$ retomada da teorização sobre o jornalismo estimula várias iniciativas, como a série de livros-reportagens São Paulo de Perfil ${ }^{3}$, além de obras teóricas como Entrevista, o Diálogo Possível $^{4}$, fruto do recorte de sua tese de doutorado, defendida em 1986.

Já nos primeiros anos da década de 1990, Cremilda Medina dá início a uma ampla divulgação das discussões acerca dos chamados saberes interdisciplinares. A autora esteve no comando do primeiro Seminário Inter e Transdisciplinar, realizado em 1990, que reuniu cientistas das mais diferentes áreas acadêmicas. As reflexões desse encontro marcam o começo do projeto Novo Pacto da Ciência ${ }^{5}$. O argumento da pesquisadora é de que o diálogo com outras vertentes do conhecimento oferece ao jornalista inúmeros subsídios para a interpretação dos acontecimentos (MEDINA, 2013). A partir de 1999, outro importante projeto interdisciplinar é liderado por Cremilda Medina. A iniciativa Signo da Relação se configurou como uma política abrangente para as mídias universitárias, pensando em novas dimensões da relação entre ciência e sociedade. Especialmente seus últimos projetos se caracterizam como espaços laboratoriais de experimentação de práticas de comunicação, lugares em que a criatividade é exercitada a partir de um intenso intercâmbio epistemológico, teórico e metodológico.

Além de vários livros de sua autoria, dezenas de coletâneas organizadas, Cremilda Medina também acumula diversos trabalhos orientados ao longo de sua trajetória como integrante dos programas de pós-graduação em Comunicação (PPGCOM) e Integração

3 Os 27 livros dessa coletânea foram produzidos, sobretudo, por estudantes de graduação (MEDINA, 2014). Já na primeira edição da série, lançada em 1987, jovens aprendizes do jornalismo se envolviam com a humanização das pautas, com a profundidade da reportagem, com a busca pela identidade cultural, além da compreensão do cotidiano, dos tempos e dos espaços da atualidade brasileira, paulistana e paulista.

${ }^{4}$ Conforme explica a autora, a Editora Ática é quem optou por acrescentar o termo "Entrevista" no título do livro, incialmente chamado apenas de "O Diálogo Possível" em sua tese. No entanto, Cremilda não situa a técnica da entrevista como o principal e único suporte do signo da relação ou do ato comunicativo (MEDINA, 2014).

5 Trata-se de um conjunto de reflexões que já conta com onze edições, todas ancoradas no caráter pluralista oriundo da troca de saberes entre ciências humanas, biológicas e exatas, bem como no encontro entre ciência e arte (MEDINA, 2013).

Revista Pauta Geral-Estudos em Jornalismo, Ponta Grossa v.5, n.2, p.89-105, Jul/Dez 2018. 
da América Latina (Prolam), ambos da USP. Na sequência, apontamos e refletimos sobre como se configuram os primeiros escritos de Cremilda Medina acerca do jornalismo.

\section{Abordagens iniciais acerca do fenômeno jornalístico}

Com a obra Notícia, um Produto à Venda, Jornalismo na Sociedade Urbana e Industrial, Cremilda Medina compreende a estrutura da mensagem jornalística no grande quadro de referência de uma sociologia da cultura. A notícia é percebida como um produto de comunicação de massa, relacionada à indústria cultural e aos contornos da sociedade urbana e industrializada. Apesar de reconhecer que esse amplo conjunto de condicionantes do produto noticioso é conformado pela cultura industrializada e massificada, Medina (1978) sinaliza limitações teóricas na perspectiva da chamada Escola de Frankfurt. Para ela, as visões apocalípticas, marcadas pelo pessimismo latente e por um olhar reduzido às determinações econômicas, são frágeis e distantes de um pensamento capaz de compreender a complexidade do jornalismo. Logo, mesmo que resguarde traços industriais e de massa, a notícia deve ser vista como um produto cultural dinâmico. Tal entendimento impossibilita situá-la num processo de estandardização absoluta (MEDINA, 1978).

No que diz respeito à classificação dos gêneros, a pesquisadora destaca três tendências já bastante assinaladas por outros estudos da área: jornalismo informativo (informação imediatista), jornalismo interpretativo (informação ampliada) e jornalismo opinativo (informação avaliada e comentada). Essa fase da pesquisa de Cremilda Medina evidencia a notícia como tipo narrativo predominante na imprensa brasileira, com duas principais funções: informar e distrair. Apreende-se que, nessa época, a autora concebe a informação jornalística como uma necessidade básica do ser humano, sem rejeitar a dimensão do lazer $^{6}$, outra demanda legítima do público. Para ela, o binômio informaçãolazer está presente em todo o processo da indústria cultural, o que costuma despertar críticas negativas e condenações, muitas vezes, apocalípticas (MEDINA, 1982).

\footnotetext{
${ }^{6}$ Essa compreensão da autora advém da percepção sobre o comportamento complexo do público já reconhecido desde estudos do século passado. Segundo Medina (1982), ao consumir um produto noticioso ou assistir a um filme, a audiência age de modo não linear, oscilando entre informação e lazer, realidade e sonho, interação social e individualização emocional. Isso não significa, é claro, que informação jornalística e produtos de entretenimento não possuam suas particularidades enquanto fenômenos midiáticos.
} 2018. 
Ainda em suas primeiras obras, Cremilda Medina define o jornalista como um técnico da informação, um produtor que precisa ter os seguintes traços em seu perfil: ética profissional; capacidades técnicas para investigar a realidade imediata; capacidade de relação com a realidade social; capacidade artística no domínio da linguagem; e vivências a serviço do enriquecimento profissional (MEDINA, 1978). Em meio a esse conjunto de aspectos atribuído ao profissional da informação, as técnicas jornalísticas são entendidas como instrumentos de trabalho, armas para operar na realidade adversa (MEDINA, 1982). A autora também reconhece o jornalista como um ser investido de um papel social específico: estabelecer pontos na realidade dividida, estratificada em grupos de interesse, classes sociais, segmentos culturais e faixas etárias.

Ao chamar a atenção para as limitações de olhares reducionistas, Cremilda Medina defende que as análises voltadas para o fenômeno jornalístico precisam dar conta de seu aspecto dinâmico e de suas variáveis partindo dele próprio, o que significa deixar de lado o menosprezo pela massa, atitude fruto do elitismo cultural (MEDINA, 1982). Em seus escritos, a pesquisadora rompe com as tradicionais perspectivas unilaterais do processo de comunicação, enfatizando a necessidade de um olhar estrutural e sociológico para analisar as conformações do fenômeno jornalístico. Tal olhar precisaria incorporar elementos da história da imprensa, bem como levar em consideração a multiplicidade de forças presentes na produção, distribuição e consumo das notícias.

O gesto de leitura sobre o fenômeno jornalístico realizado por Cremilda Medina é criticado por Adelmo Genro Filho em O segredo da pirâmide: para uma teoria marxista do jornalismo. Para este autor, Medina (1978) identifica o jornalismo integralmente como mensagem-consumo, isto é, em sua conformação exclusivamente mercantil. Considera, ainda, que a pesquisadora é pouco crítica ao capitalismo, mesmo trazendo pressupostos da Escola de Frankfurt. Genro Filho (1987), então, enquadra o pensamento de Medina (1978) como funcionalista, criticando seu desprendimento de uma perspectiva revolucionária para pensar o potencial da atividade jornalística. Todavia, como já destacamos, Cremilda Medina argumenta, ainda em seus primeiros estudos, que a teorização do jornalismo não pode ser elaborada apenas levando em conta fatores econômicos, devendo incluir elementos mais amplos da cultura e da conjuntura social em que os meios de comunicação desempenham suas atividades. Ademais, é oportuno pontuar que, em seu trabalho, Genro Filho (1987) não reconhece a defesa de Cremilda Medina por um pensamento complexo e dinâmico para pensar o fazer jornalístico. PodeRevista Pauta Geral-Estudos em Jornalismo, Ponta Grossa v.5, n.2, p.89-105, Jul/Dez 2018. 
se questionar, ainda, a ausência de outras obras da autora ${ }^{7}$ na crítica elaborada por Adelmo Genro Filho, que cita apenas o livro Notícia, um produto à venda: jornalismo na sociedade urbana e industrial.

Como veremos na sequência deste artigo, a divisão dos gêneros e as finalidades do relato jornalístico, bem como os papéis do sujeito jornalista recebem tratamento mais aprofundado em textos das décadas seguintes da pesquisadora. Isso se deve, em grande medida, por conta da aproximação com novas questões teóricas que passaram a ocupar espaço nas reflexões de sua autoria.

\section{Quando a dialogia se manifesta}

Ao longo da década de 1980, Cremilda Medina passa a se envolver mais fortemente com a questão da dialogia nos processos da comunicação social, em especial, do jornalismo. No livro Entrevista: O Diálogo Possível ${ }^{8}$, observa uma série de problemas nos modos de condução das entrevistas no jornalismo, bem como no tratamento dado as falas dos entrevistados. A autora afasta a compreensão da entrevista como uma simples técnica burocrática, enfatizando o caráter dialógico dessa etapa do fazer jornalístico. Aliás, não reconhece as fases do processo de produção noticiosa (pauta, entrevista, apuração, edição e narração) como unidades estanques e independentes, uma vez que estamos diante de um fenômeno - o jornalismo - dinâmico e essencialmente relacional. Essa perspectiva adotada pela pesquisadora está vinculada ao entendimento da comunicação como um ato que interliga, une, comunga os diferentes sujeitos e pontos de vista existentes numa dada sociedade. Neste caminho conceitual, a entrevista deve ser percebida como lugar de interação social, de interpenetração informativa, um momento

\footnotetext{
7 No intervalo temporal que separa as obras Notícia, um produto à venda: jornalismo na sociedade urbana e industrial, de 1978, e O segredo da pirâmide: para uma teoria marxista do jornalismo, de 1987, Cremilda Medina produziu outros textos teóricos sobre o jornalismo, incluindo as reflexões presentes nos livros Profissão Jornalista: responsabilidade social, de 1982 e Entrevista: O Diálogo Possível, de 1986, ambos referenciados neste presente artigo.

8 Publicação extraída da tese de doutorado intitulada Modo de Ser, Mo' Dizer, defendida em 1986, na USP.
} 
capaz de quebrar isolamentos grupais, individuais, sociais, podendo ainda colaborar para a pluralização de vozes e distribuição democrática da informação (MEDINA, 1986).

Vale sublinhar que outra preocupação de Cremilda Medina, desde os anos 1980, era ressaltar a complexidade inerente a qualquer produto cultural, como é o caso da notícia. Conforme explica, há uma complexa rede de forças que atua sobre o fato jornalístico. Por isso, ao se lançar numa pesquisa (ou ato de decifração), o jornalista mergulha numa "verdade" de muitas faces, contradições, espaço em que sua atuação é sempre relativa, sua especulação é limitada, seu comportamento nunca é totalmente objetivo, cientificista, como pretendem os clássicos do mito da objetividade (MEDINA, 1986). O papel do jornalista como mediador também é problematizado em Povo e Personagem, livro em que a autora enfatiza que o profissional da informação articula nas relações simbólicas o universo das ideias. Ao mesmo tempo, cabe ao comunicador social especializado na produção jornalística trabalhar com o imaginário coletivo, emoções, mitos e registros intuitivo-criativos (MEDINA, 1996).

A discussão sobre a dialogia na prática da entrevista, bem como em outros momentos da produção noticiosa, recebe contribuições teóricas de diferentes vertentes, partindo desde a filosofia da linguagem de Mikhail Bakhtin até a perspectiva conceitual de Edgar Morin ${ }^{9}$. O ato de narrar é reconhecido pela autora como uma ação que busca reproduzir simbolicamente a realidade. O jornalista-autor de uma narrativa desse tipo é considerado um mediador simbólico. Para Cremilda Medina, só o jornalista que se aperfeiçoa para poder criar terá alguma possibilidade de intervir no chamado processo de mediação social. Desde os anos 1980, portanto, a autora já demarcava a necessidade de os jornalistas superarem os obstáculos da profissão e investirem em apurações e narrações dialógicas e complexas. Assim é que tornariam-se capazes de modificar efetivamente o status quo e praticar um discurso polifônico (diversidade de vozes) e polissêmico (multiplicidade de significados).

Em estudo de Fabio Henrique Pereira, a perspectiva de Cremilda Medina acerca da entrevista é circunscrita a uma dimensão estritamente de caráter técnico-normativo, no qual as tipologias desse gênero jornalístico e os modos como o jornalista deve agir são enfatizados em detrimento de aspectos de ordem mais teórico-conceitual, estes também

\footnotetext{
9 No artigo A entrevista nas Ciências Sociais, na rádio e na televisão, de 1973, este autor circunscreve fronteiras entre as entrevistas das ciências sociais e do jornalismo. 2018.
} 
fortemente presentes na produção acadêmica da autora. Apesar de Pereira (2017) mencionar brevemente a defesa de Medina (1986) no que concerne ao diálogo entre entrevistador e entrevistado, não se observa, em sua crítica, um entendimento apurado sobre o que constitui esse espaço dialógico - uma interação social criadora - reivindicado pela autora. O olhar crítico de Cremilda Medina diante do tecnicismo dos manuais e normas de redação para pensar a entrevista é mais precisamente apreendido na pesquisa de Agnes Francine de Carvalho Mariano. Esta pesquisadora reconhece a importância da abordagem mais complexa do ato de entrevistar proposta em Medina (1986). Contudo, ressalva que tal perspectiva não está livre de algumas zonas silenciosas, estas vinculadas às definições poéticas, mas vagas sobre a abertura do diálogo nas entrevistas (MARIANO, 2018).

É preciso sublinhar que Medina (1996) insiste numa mediação dialógica argumentando que a própria demanda social por informação não se satisfaz com as fórmulas reducionistas dos manuais de jornalismo. Também torna-se indispensável reconhecer que o público consumidor da produção jornalística é complexo e ativo, mesmo que sua relação com os meios se desenvolva assimetricamente. Nesta linha de pensamento, o trabalho do jornalista é um processo decifrador, cognoscitivo, no qual se expressa uma cosmovisão. Cremilda Medina, no entanto, compreende que, para além deste esforço racional, o jornalista administra pressões externas e sentimentos coletivos, mesmo que, muitas vezes, inconscientemente. Devido a complexidade inerente ao fazer dos profissionais, acaba por ser frequente a produção de narrativas na contramão da dialogia: Surgem, por conta disso, relatos que se encantam pelas visões oficiais dos fatos, constituindo-se, na verdade, em narrativas monológicas. Para a autora, o pensamento que fragmenta e coisifica a comunicação é responsável por uma compreensão simplista acerca do sujeito jornalista.

É explícita sua crítica à estrutura e ao modelo estanque da pirâmide informativa. Cremilda Medina nos lembra que o real pulsante não pode ser transportado para uma ata de ritmo previsível da primeira à última informação. Sua perspectiva, então, assume a necessidade de outros elementos (maleabilidade narrativa) para decifrar o real imediato, objetivo, em especial, das notícias. O que a pesquisadora discute nessa fase de sua trajetória se relaciona, ainda, com a chamada humanização do jornalismo, discussão elaborada com mais densidade em escritos posteriores. 


\section{Uma perspectiva complexa para ler o jornalismo}

$\mathrm{Na}$ esteira do segundo milênio, inscrito em uma série de novos dilemas de ordem econômica, política, tecnológica e sociocultural, Cremilda Medina dá continuidade ao estudo das interfaces do fenômeno jornalístico, refinando sua análise com base em contribuições de Edgar Morin, Boaventura de Souza Santos e Milton Greco, entre outros autores. A necessidade de uma perspectiva efetivamente complexa para compreender o jornalismo passa a ser mais discutida. Tal complexidade, no entendimento da autora, só é possível de ser alcançada a partir de uma intensa prática interdisciplinar e transdisciplinar, que conjuga saberes diversos e abdica de pensamentos fechados e pretensiosamente considerados inquestionáveis. Ao reconhecer o potencial e os limites de conhecimentos de estatutos variados - tais como: o teórico, o profissional, o popular, o artístico, o religioso -, a pesquisadora aprofunda a investigação sobre as atrofias éticas, estéticas e técnicas da atividade jornalística.

Para Cremilda Medina, diante da consciência dos limites e das contradições do saber científico clássico de caráter positivista - o mesmo que legitima o princípio da objetividade -, torna-se oportuno problematizar o jornalismo a partir de uma epistemologia pragmática que valorize a complexidade e a interconexão de conhecimentos diversos. Essa nova forma de olhar o fenômeno jornalístico, bem como para outras atividades comunicacionais, advém da percepção de que a contemporaneidade reclama pela dialogia interativa (MEDINA, 2006). É por isso que, para a autora, o jornalismo enquanto profissão não perde importância nos dias de hoje, mesmo com o aparecimento e fortalecimento de novos canais de expressão. Pelo contrário, ganha peso a necessidade de um mediador que articule significados e dê conta da regência de vozes numa sociedade cada vez mais complexa em termos de demandas individuais e coletivas.

O comunicador social voltado para a produção da narrativa jornalística, segundo Cremilda Medina, deve ser reconhecido como um leitor privilegiado da cultura, uma vez que transita numa primeira realidade, observa o mundo a sua volta, capta depoimentos e relaciona sentidos em suas mediações que ganham forma de notícia, reportagem ou outro tipo de relato. É também fundamental a compreensão de que as técnicas empregadas na seleção, apuração, edição e narração do produto jornalístico não são assépticas, mas responsáveis e esteticamente inovadoras e solidárias. A autora rechaça a concepção do jornalista como um difusor de informações que apenas conforma o grande público. Para 
Cremilda Medina, é preciso visualizar o potencial do jornalista como artesão criativo do diálogo transformador da ciência e do saber cotidiano.

Em Ciência e Jornalismo: da herança positivista ao dialogo dos afetos, Cremilda Medina nos lembra que a cobertura do real imediato, seja uma notícia ou reportagem, se serve das gramáticas que se disciplinaram no final do século XIX, no ambiente cientificista da modernidade ocidental. A autora explica que o jornalismo brasileiro é caudatário da experiência anglo-saxônica, que resguarda fortes marcas do funcionalismo. Não é por acaso que os relatos sobre o presente costumam ser construídos envoltos a valores, premissas, orientações e técnicas associadas a postulados positivistas. Resulta disso um produto jornalístico na contramão da vã erudição, se firmando no terreno do imediato, reunindo dados precisos, se aproximando no tempo e no espaço do real concreto. Para Medina (2008), por exemplo, existem várias semelhanças entre a metodologia da pesquisa empírica nas ciências sociais e a metodologia da reportagem jornalística. Em síntese, de acordo com a autora, o culto à objetividade; a afirmação de dados concretos referentes aos fatos; a precisão da linguagem; a fuga de abstrações, a estrutura do lead (o quê, quem, quando, como, onde, por quê) e a própria lógica da pirâmide invertida (a disposição das informações em ordem decrescente de importância), até certo ponto, refletem os cânones e dogmas da filosofia positivista.

Medina (2003), em outra obra ${ }^{10}$, já havia argumentado que o discurso cientificista da objetividade e da busca da verdade se caracteriza como um frágil escudo para defender praticas jornalísticas reducionistas. As narrativas jornalísticas, na visão da autora, possuem um déficit de criatividade histórico quando assentadas e fechadas em princípios e valores do cientificismo. Os paradigmas operacionais que se aplicam ao fazer jornalístico são oriundos do acúmulo de conhecimentos e gramáticas pouco abertas à dialogia, ao outro, à necessária humanização das narrativas. Para Medina (2003), se o jornalismo almeja, de fato, a ação solidária na contemporaneidade, terá que pesquisar, sensibilizar-se e praticar as dialogias. As técnicas jornalísticas, ancoradas no paradigma

10 Em nova versão de A arte de tecer o presente: Narrativa e Cotidiano, publicada em 2003, a autora explora os impactos da crise epistemológica no fazer jornalístico. Como já mencionado neste presente trabalho, três décadas antes, em 1973, Cremilda Medina publicou em parceria com Paulo Roberto Leandro uma obra com esse mesmo título. Nesse primeiro livro, os autores se dedicaram à investigação das tendências da reportagem jornalística no Brasil.

Revista Pauta Geral-Estudos em Jornalismo, Ponta Grossa v.5, n.2, p.89-105, Jul/Dez 2018. 
positivo-funcionalista, acabam, não raras vezes, por estimulando e reforçando a criação de relatos reducionistas que tendem a simplificações e preconceitos acerca de pessoas, grupos, situações e temas. Isso pode ser verificado, conforme exemplifica Medina (2006), nas narrativas recorrentes do jornalismo em que imperam as noções de certo e errado, de causa e efeito e de sujeito e objeto.

Cremilda Medina vislumbra o jornalismo como o fenômeno mais consagrado que compõe a comunicação social. Trata-se, segundo a autora, do fenômeno responsável por dar conta da tessitura dos nexos, isto é, da articulação competente e responsável dos significados encontrados nos mais diferentes segmentos de uma sociedade. Por conta da complexidade dos acontecimentos selecionados para serem narrados, é indispensável que o jornalista seja aquilo que Medina (2003) chama de agente cultural sensível e capacitado para mediar grupos, comunidades e indivíduos numa rede comunicacional. Outro aspecto bastante reiterado é a atuação do jornalista na rua. Conforme defende a pesquisadora, o jornalista, reconhecido como mediador-autor, recebe do gesto e da voz do saber cotidiano inspiração que não se circunscreve nas ideologias de grupos nem em um paradigma científico absoluto. Cremilda Medina entende, assim, que a efetiva mediação e autoria exige uma entrega afetuosa ao outro, bem como um esforço para compreender as diferentes visões de mundo que coexistem e que, muitas vezes, entram em conflito. Para entender e praticar complexamente o jornalismo, é preciso, no entanto, assumir que "partilhar a visão de mundo do outro, dela extrair a utopia humana e ampliar a competência técnica e científica na narrativa solidária não é uma miragem, é uma possibilidade (MEDINA, 2003, p. 80)".

A problemática do ato dialógico - que extrapola o espaço da entrevista defendido por Cremilda Medina é tensionada por Sylvia Moretzsohn no livro Pensando contra os fatos: jornalismo e cotidiano: do senso comum ao senso crítico. Na ótica desta autora, por mais que o exercício do diálogo seja viável em determinadas circunstancias, cabe uma relativização de tal perspectiva da "descoberta do outro". Esse entendimento está associado à percepção do ritmo veloz e do ambiente midiatizado em que as entrevistas jornalísticas se desenrolam, aspectos que alteram a qualidade da relação entre os sujeitos entrevistador e entrevistado (MORETZSOHN, 2007). Já Fernando Rezende, no artigo O jornalismo e a enunciação: perspectivas para um narrador-jornalista, considera as empreitadas teóricas de Cremilda Medina como intervenções contundentes por renovarem o olhar sobre os exercícios do pensar e fazer jornalístico. Trata-se, Revista Pauta Geral-Estudos em Jornalismo, Ponta Grossa v.5, n.2, p.89-105, Jul/Dez 2018. 
conforme o autor, de um tipo de pesquisa que reflete acerca das dissonâncias entre uma prática autoritária e uma dimensão mais complexa (RESENDE, 2005).

Uma leitura apressada da obra de Cremilda Medina pode chegar à equivocada compreensão de que a autora rejeita e menospreza todas as técnicas e princípios historicamente presentes no fazer jornalístico. Contudo, o que a autora reivindica é um olhar crítico perante eles, uma perspectiva complexa que deve partir do próprio sujeito jornalista. Afinal, como Medina (2008) argumenta, há momentos em que o profissional, mesmo sendo um experiente técnico no ato de narrar, é colocado à prova diante de situações-limite do acontecimento imediato. Embora a consciência racional, o traquejo especializado e a persistência na ação possam ser importantes ferramentas para o trabalho disciplinado, a pesquisadora nos lembra que a prática do jornalista também necessita do silêncio subjetivo, dos sinais dos cinco sentidos, bem como da despoluição da consciência para a escuta da interação criadora. Outra reivindicação da autora é que a experiência social, os comportamentos da época, assim como a saga dos anônimos sejam narrados a partir do chamado signo da relação. Medina (2007) elucida que esse signo de caráter relacional, ao contrário do mero signo da divulgação que busca certezas com suas técnicas convencionais ${ }^{11}$, se move no horizonte do desconhecido, do misterioso e do imprevisível.

Medina (2006) considera que a construção de sentidos realizada pelo jornalismo possui um caráter processual. No entanto, observa que as técnicas da narrativa tendem quase sempre para o enquadramento do real, a atrofia de sua vitalidade enquanto processo. Para a autora, quando se encara um determinado fato como um momento visível da história passível de ser representado numa pirâmide invertida, disposto no formato lead, em esquemas textuais e imagéticos extremamente padronizados, não é possível responder ao movimento e aos conflitos do ato social. Um dos fatores que inibe o potencial criativo e relacional do jornalismo é a desconsideração das incertezas, das

11 Para Cremilda Medina, no signo da divulgação - muitas vezes presente na disseminação da ciência, prática comum no jornalismo científico -, o jornalista, no máximo, atua como tradutor linguístico de um relato mais acessível para um público não especializado. O signo da relação, conforme Medina (2013), envolve mudança de mentalidades, visões de mundo e comportamentos. Exige o reconhecimento de que os fatos nem sempre possuem apenas uma causa ou consequência, visto que são multidimensionais e complexos. 
rugosidades e ambiguidades que constituem tanto o acontecimento social quanto a experiência dos protagonistas no cotidiano (MEDINA, 2008). É basilar, portanto, que toda a prática jornalística que se propõe competente, responsável e autoral, consiga ir além dos limites consagrados da razão.

Em trabalhos mais recentes, Cremilda Medina reafirma a necessidade de uma construção teórica do jornalismo - e da comunicação social, campo maior nunca deixado de lado pela pesquisadora - que leve em conta a complexidade da narrativa dialógica. Para tanto, se coloca como fundamental perseguir todas as composições interativas que se desenvolvem com os saberes plurais (MEDINA, 2013). A autora insiste na aproximação do jornalismo, em termos de prática e pesquisa, com outras áreas, como a arte. Esse contato renovaria a dimensão criativa e relacional das produções jornalísticas. Em seus exercícios epistemológicos, cada vez mais assentados na interdisciplinaridade, a pesquisadora considera que o entrecruzamento de perspectivas e metodologias científicas colabora com a desconstrução de paradigmas dogmatizados que comandam as operações do fazer jornalístico.

Num contexto permeado pela constante atualização de tecnologias e sistemas organizacionais, Medina (2018) verifica que as narrativas da contemporaneidade desafiam os profissionais da informação a partir de um conjunto mais amplo de paradigmas, visões de mundo e comportamentos. Para a pesquisadora, é cada vez mais oportuno investir em reportagens com traços ensaísticos, visto que a multiplicidade sócio-político-econômicacultural do mundo contemporâneo não pode ser representada em padrões reducionistas, frequentes em relatos jornalísticos que ignoram a complexidade e as indeterminações do presente.

\section{Considerações finais}

No desenrolar das cinco décadas de teorização sobre o jornalismo, as reflexões de Cremilda Medina abarcam tendências e temáticas de pesquisa que foram sintetizadas e discutidas neste trabalho. O fenômeno jornalístico, conforme a perspectiva defendida pela autora, está indissociavelmente circunscrito num campo maior, a comunicação. Tal concepção traz consigo implicações conceituais que podem ser compreendidas especialmente em sua constante reivindicação por olhares inter e transdisciplinares para pensar e discutir a teoria e prática da profissão. Apesar de o jornalismo ser reconhecido como uma das várias atividades comunicacionais com traços industriais, culturais e Revista Pauta Geral-Estudos em Jornalismo, Ponta Grossa v.5, n.2, p.89-105, Jul/Dez 2018. 
midiáticos, Cremilda Medina visualiza e problematiza uma série de aspectos que caracterizam a prática jornalística como um fazer particular.

Com base na perspectiva desta autora, compreende-se o relato jornalístico, seja na forma de uma notícia ou reportagem, como uma representação simbólica resultado da mediação social desempenhada por leitores culturais privilegiados, os jornalistas. A narrativa configurada pelo jornalismo resguarda, assim, a função de organizar as tessituras dos nexos, articulando de maneira competente e responsável os significados e as vozes que constituem os acontecimentos sociais. Esse ato de narrar o real, Cremilda Medina nos lembra, se firma no terreno do imediato, congrega uma linguagem precisa e pretensiosamente - objetiva, bem como se abeira no tempo e no espaço do concreto. Neste caminho, entende-se que a narrativa jornalística expressa, a partir de uma cosmovisão, a necessidade de reagir ao caos da história. Emerge daí o papel historicamente atribuído ao jornalismo: organizar - selecionar, apurar, editar, narrar - as complexas tramas da realidade. Essa concepção identifica o trabalho do sujeito jornalista como uma prática decifradora e cognoscitiva, voltada para uma necessidade básica do ser humano: se informar. No entanto, tal demanda não se encapsula apenas em fatores racionais, uma vez que as produções jornalísticas incorporam, em diferentes medidas, emoções, mitos e registros intuitivos-criativos que permeiam o imaginário coletivo (MEDINA, 2006).

Muitos dos dilemas associados ao jornalismo podem ser explicados pela ausência de um olhar complexo e relacional, que entenda a atividade comunicacional-jornalística como um exercício dialógico, um ato solidário aberto à compreensão do outro. O signo da relação defendido por Cremilda Medina é uma perspectiva que assume os limites das técnicas jornalísticas tradicionais, sem receio de se mover no âmbito do desconhecido, do incerto e do imprevisível. Na contramão das verdades únicas e absolutas, está colocada a possibilidade de que a produção simbólica do jornalismo se desprenda das travas ideológicas alimentadas por certezas - fruto da consolidada gramática positivista - e se abra para a compreensão complexa, contraditória e conflitiva da realidade (MEDINA, 2013). Engata-se aí outra valiosa contribuição de Cremilda Medina para pensar o jornalismo: a chamada arte de tecer o presente, sendo ato relacional e dialógico, é um fazer que não dispensa a razão complexa, a sensibilidade intuitiva, o comportamento solidário e a estética inovadora. 
Em tempos em que a atividade jornalística enfrenta profundas transformações estruturais, que incluem intensos processos de convergência digital, alterações na forma de sustentação fincaneira dos veículos e precarização das condições de trabalho dos profissionais, a perspectiva teórica de Cremilda Medina, numa primeira avaliação, pode parecer um tanto idealista. Todavia, o necessário olhar dialógico também compreende os limites da realidade concreta e difícil em que o jornalismo é exercido. Essa visão crítica busca superar as dificuldades da vida social e profissional, aproveitando cada brecha possível para a realização de um jornalismo que observe, interprete e relate o mundo de maneira complexa.

\section{Referências Bibliográficas}

GENRO FILHO, Adelmo. Segredo da pirâmide: para uma teoria marxista do jornalismo. Porto Alegre: Tchê!, 1987.

MARIANO, Agnes Francine de Carvalho. A entrevista como tema de pesquisa no campo da comunicação. Revista Famecos: mídia, cultura e tecnologia. Porto Alegre, RS. V. 25, n.2, p; 01-17, 2018.

MEDINA, Cremilda. A arte de tecer o presente - narrativa e cotidiano. São Paulo: Summus, 2003.

. Apontamentos epistemológicos a propósito da crise brasileira. Porto Alegre, RS. n. 42, p. 77-96, 2018 Summus, 2008.

Ciência e Jornalismo - da herança positivista ao diálogo dos afetos. São Paulo: . Entrevista - O diálogo possível. São Paulo: Ática, 1986.

Jornalismo e signo da relação: a magia do cinema na roda do tempo. In: Rev. Líbero, ano X, nº 19, Jun 2007. (p.17-25).

Memórias: viradas dos anos 1960. Intexto, Porto Alegre, UFRGS, n. 34, p. 770781, set./dez. 2015

Narrativas da contemporaneidade: epistemologia do diálogo social. Tríade, Sorocaba, v. 2, n. 4, p. 8-22, 2014.

Notícia, um produto à venda. São Paulo: Alfa-Omega, 1978.

2013.

Novas manifestações, velhos paradigmas. In: MATRIZes, Ano 7, nº 2, jul./dez. $\overline{2006 .}$

O signo da relação - Comunicação e pedagogia dos afetos. São Paulo: Paulus, 
Povo \& personagem. Canoas: Ulbra, 1996.

Profissão Jornalista: responsabilidade social. Rio de Janeiro: Forense Universitária, 1982.

MORETZSOHN, Sylvia. Pensando contra os fatos - Jornalismo e cotidiano: do senso comum ao senso crítico. Rio de Janeiro: Revan, 2007.

PEREIRA, Fabio Henrique. A entrevista no jornalismo brasileiro: uma revisão de estudos. Revista Estudos em Jornalismo e Mídia. Florianópolis, SC. V. 14, n.2, p. 139149, 2017.

RESENDE, Fernando. $O$ jornalismo e a enunciação: perspectivas para um narradorjornalista. In: Contracampo. Niterói: IACS/UFF, 2005.

Recebido em: 06/07/2018

Publicado em: 21/12/2018 